\title{
Propriedade privada, crítica da reificação e a socialização dos meios de produção
}

\author{
Private property, critique of reification and the \\ socialization of the means of production
}

Hauke Brunkhorst*

\begin{abstract}
Resumo: O problema de uma sociedade que se baseia na propriedade privada dos meios de produção consiste nas condições desiguais e injustas de geração de riqueza econômica e de poder político. No conceito burguês de propriedade privada combinamse a reificação de conceitos universais com os interesses de classe do capital. A Filosofia do direito, de Hegel, exemplifica isso de modo paradigmático. No presente texto é feita uma tentativa de mostrar que a ideia do socialismo democrático, que interconecta a socialização dos meios de produção com a dominação política exercida pelos dominados, de modo algum é uma utopia extravagante. Embora as chances de realizá-la atualmente sejam poucas, a ideia de um socialismo democrático ainda é uma alternativa viável.
\end{abstract}

Palavras-chave: Justiça distributiva. Reificação. Emancipação. Democracia. Socialismo.

The problem of a society based on private property of productive forces are the unequal and unjust conditions of producing economic wealth and political power. The bourgeois legal concept of private property is a paradigmatic combination of the reification of universal concepts and class-interest. An exemplary case is Hegel's Philosophy of law. The essay tries to reconstruct the idea of democratic socialism as a still workable alternative.

Keywords: Distributive justice. Reification. Emancipation. Democracy. Socialism.

\footnotetext{
* Doutor e livre-docente em Filosofia pela Universidade de Frankfurt (Alemanha), diretor do Departamento de Direito da Europa e Direito Internacional e professor de Sociologia na Europa-Universität Flensburg (Alemanha). Publicações recentes: Critical theory of legal revolutions: evolutionary perspectives (London: Bloomsbury, 2014); Das doppelte Gesicht Europas: Zwischen Kapitalismus und Demokratie (Frankfurt: Suhrkamp, 2014); Kritik und Kritische Theorie: Programme, Personen, Positionen (Baden-Baden: Nomos, 2014); Legitimationskrisen: Verfassungsprobleme der Weltgesellschaft (Baden-Baden: Nomos, 2012) <brunk@uni-flensburg.de>. Tradução do alemão: Emil A. Sobottka.
} 
A curva em U que Colin Crouch (2004, p. 5, 20-30) já tinha tomado como base para seu tratado sobre a crise da democracia igualitária de massas, e que se tornou mundialmente famosa pelo estudo de longo prazo de Thomas Piketty (2014, p. 23-26, 195-196, 402-403) sobre a tendência ascendente da taxa de lucro, permite divisar em um relance a catástrofe para a qual caminha o capital no século 21. A distribuição de renda e de patrimônio imposta globalmente a partir de cima, numa luta de classes que já dura trinta anos e nas condições estruturais de baixas taxas de crescimento, retornou hoje ao seu nível de partida do ano 1900, quando a riqueza estava concentrada em cada vez menos mãos e as diferenças sociais haviam assumido proporções grotescas. Em consequência, as instituições democráticas estão sob pressão. O número de votantes está declinando globalmente, mas sobe no decil superior, por vezes a mais de $90 \%$. Este grupo vota, como na antiga República Democrática Alemã, sempre no mesmo partido com uma agenda neoliberal. Enquanto isso, o número de votantes cai na metade inferior da sociedade, por vezes inclusive abaixo de 30\%. Quando entrevistada, a grande maioria dos não-votantes, contudo, admite que votaria numa opção socialista se ainda houvesse um partido que pudesse oferecer um programa deste tipo com alguma chance de êxito (cf. Schäfer, 2013). Devido ao fato que a média do eleitorado efetivo continua se deslocando sempre mais para a direita e em direção ao terço superior da sociedade de classes, no entanto, os partidos de esquerda são prisioneiros de uma timidity trap (Krugman, 2014), que dita aos partidos que eles devem jogar ao mar o lastro esquerdista e empenhar-se em pescar na faixa superior à direita, onde ainda é possível conquistar poder - um poder que, no entanto, não consegue mais colocar em prática políticas alternativas. Assim a democracia torna-se a fachada de políticas onipresentes de austeridade, bem ao sabor dos interesses de um punhado de investidores, bancos e conglomerados globalmente ativos, que hoje dispõem de um poder econômico inigualável para extorquir (cf. Streeck, 2011; Bofinger et al., 2012). A cada momento, a próxima regra impositiva de austeridade deve estar pronta antes que a bolsa de valores de Tóquio abra as suas portas na manhã de domingo, às 5 horas pelo fuso horário da Europa Central.

\section{2}

A injustiça gritante da distribuição desigual da riqueza socialmente produzida e apropriada sobretudo privadamente, tal qual no século 19, há muito tempo não pode mais ser racionalizada com base no desempenho ou em méritos atribuíveis individualmente - e muito menos por teorias mais sofisticadas de justiça distributiva, que, como a de Rawls, se orientam pelo bem-estar dos 
perdedores da concorrência universal (cf. Piketty, 2014, p. 26-27, 330-331). Nas estratosferas superiores da sociedade, a riqueza cada vez mais raramente é conquistada através de uma laboriosa combinação cooperativo-repressora de gestão e exploração; cada vez mais frequentemente ela é uma herança de ativos, adquiridos sem labor próprio, para a qual apenas os outros trabalham (ibid., p. 240-243, 377-429). O shareholder-value tornou-se a medida onipresente de todas as coisas, ao passo que o poder de pressão econômica a partir de baixo, o direito à greve, tornou-se um direito meramente nominal no papel, que há mais de trinta anos dificilmente é exercido. Enquanto os escalões inferiores dentre os shareholder, juntamente com os sindicatos, são destituídos de seu poder e o cliente-rei é promovido a colaborador não-remunerado nos shopping centers, tanto as heranças bilionárias como os rendimentos e bônus dos altos executivos de conglomerados financeiros e comerciais de atuação global foram dissociados de qualquer relação reconhecível com o tempo e o desempenho do trabalho (Crouch, 2011; Streeck, 2011).

Mas as teorias da justiça meramente distributivas, orientadas para o resultado, de qualquer maneira são insuficientes. Elas têm a deficiência, já apontada por Marx, de se fixarem unicamente na distribuição passivo-receptiva de bens de uso e de troca, e, com isso, como bem observa Rainer Forst,

(1) não apenas ocultam a produção da riqueza pelo "trabalho vivo" na economia (Marx),

(2) mas também negligenciam a participação da autoridade legislativa; e

(3) do discurso público de grupos e classes em luta na produção, estabilização e alteração das respectivas relações de distribuição e de produção.

Através da fixação unilateral no resultado da distribuição, a diferença entre injustiça social, exploração e opressão, de um lado, e a mera necessidade e o desamparo causados por situações sociais de escassez, acidentes ou desastres naturais, por outro, é negligenciada (Forst, 2014). Enquanto a interdependência ético-social dilacerada pela injustiça mobiliza os poderes vingadores para despertar nos próprios afetados a "sensibilidade para a injustiça" (Barrington Moore), a necessidade pode apenas apelar para a generosidade assimétrica dos outros. Para as teorias da justiça que levam em conta esta diferença, a tarefa de que se trata é a abolição das causas sociais e da desigualdade na origem, expressa através de uma distribuição desigual cada vez mais grotesca (Kreide, 2013; 2013a). Com isto, no entanto, a teoria normativa da justiça se insere na teoria explicativa da sociedade e se transforma numa crítica das relações de 
produção (Marx) e das relações voltadas ao entendimento (Habermas) que, com a criação e re-estabilização da dominação (de classe) política e extrapolítica, produzem esta distribuição desigual da riqueza. ${ }^{1}$

\section{3}

A crítica ao ocultamento das condições sociais de produção da injustiça social pelas teorias da justiça distributiva remete a críticos mais antigos, sobretudo marxistas (Lukács), pragmáticos (Dewey), mas também juspositivistas (Kelsen), da filosofia e da ciência burguesas. ${ }^{2}$ Esta crítica, que em termos cronológicos remonta à constelação dos jovens hegelianos, tem (1) um lado objetivo (2) e outro social. Isso faz necessária (3) uma correção sócio-histórica, mas não o abandono do conceito abstrato de igualdade.

(1) Objetivamente, ela se aproxima das críticas da filosofia fenomenológica, hermenêutica e analítico-linguística do século 20 à reificação do universal (Quine) pela ontologia e pela filosofia da consciência. ${ }^{3}$ Criticadas são, por um lado, a dominação da metáfora da reflexão (Rorty) e, por outro, a do conceito (Adorno). Por uns é rejeitado o primado da representação cognitiva (Austin) e pelos outros, a hegemonia da razão instrumental (Horkheimer). Foco da crítica é a metafísica dualista; ela assume que expressões linguísticas para algumas classes de possíveis objetos se referem a algo que não foi produzido conceitualmente nem pela práxis humana; não sendo produzido, este algo seria, portanto, imutável (Quine, 1961, p. 123). A ontologia e a filosofia da consciência "objetivaram" a reflexão sobre as nossas práticas de entendimento "imediatamente como um ser suprassensitivo [einen übersinnlichen Seienden]" (Tugendhat, 1976, p. 51). A definição de verdade como correspondência (ou semelhança) entre sentenças e coisas é o protótipo de exemplo de uma reificação da nossa práxis, de assegurar-nos da validade de sentenças controversas em processos e discursos intersubjetivos. Também o veritativo ser é um para-ser (zu-sein, to be) (ibid., p. 484-494). Assim como os antigos profetas polemizaram contra a reificação do seu Deus universal como ídolo divino em madeira, o pragmatismo polemiza contra a reificação de pretensões de verdade universais, com as quais nós nos comprometemos perante os outros no uso temporalmente

\footnotetext{
${ }^{1}$ Sobre este tipo de teoria, cf. Habermas (1983).

2 Adeptos do pragmatismo frequentemente preferem a expressão "aristocrático" para incluir num único caldeirão todo o pensamento de Platão a Hegel.

${ }^{3}$ Frequentemente combinada com uma classificação histórico-genética em ontologia, filosofia da consciência e análise linguística (linguistic turn) ou em pensamento pré e pós-metafísico (cf. Apel, 1973; 2011; Tugendhat, 1976, p. 35-51, 80-104; Rorty, 1980; Schnädelbach, 1985, p. 47-76; Habermas, 1988, p. 20-26, 35-60).
} 
situado da linguagem, como entidades atemporais. "When we go, so do our norms and standards of rational assertibility. Does truth go too? Truth neither comes nor goes. That is not because it is an entity that enjoys an atemporal existence, but because it is not an entity at all. The word 'truth' in this context is just the reification of an approbative and indefinable adjective" (Rorty, 1993, p. 453). Com argumentos semelhantes Hans Kelsen criticou a assimilação da normatividade do direito à facticidade do poder, a deificação do estado e a reificação da produção e legitimação legalmente organizadas do direito à legitimidade superior de uma soberania estatal por trás do direito (Kelsen, 1960; 1981, p. 45-46; cf. Möllers, 2001, p. 251, 254-255). Na medida em que são fixadas num ser suprassensível, as práticas voltadas ao entendimento geradoras de significado tornam-se uma segunda natureza fetichizada, através da qual relações sociais entre pessoas e conceitos criados por pessoas são reconvertidos em relações naturais reificadas. Relações sociais jurídicas são reinterpretadas pelo positivismo burguês da razão de estado como relações naturais e, desta maneira, "justificadas", "transfiguradas" e "mascaradas" (Kelsen, 1967, p. 73).

(2) A transição da crítica factual da reificação do universal para a crítica prática das barreiras sociais de classe de uma maneira filosófica ou científica de pensar é especialmente plausível quando as relações de dominação "entre pessoas" assumem o "caráter de uma substancialidade" e de uma "objetividade fantasmagórica", pela qual se "encobre" o fato que se trata de uma "relação" temporal e mutável "entre pessoas" (Lukács, 1923, p. 94). Nesses casos, a vinculação latente a interesses materiais e intelectuais de classe ajuda a explicar inconsistências e anomalias do respectivo programa de investigação. John Dewey, por exemplo, na década de 1920 explicou a reificação ontológica do universal por meio da proximidade da metáfora ótica em relação à distinção aristocrática: o olhar de cima para baixo que o ouvido saturado, orientado para o entendimento, supera no modo simétrico da participação democrática (Dewey, 1984, p. 371). Quase ao mesmo tempo, Lukács explica as antinomias do pensamento burguês a partir de seu confinamento ao interesse burguês de classe. Se bem que o recuo transcendental-filosófico da crítica (neokantiana) às "condições formais de validade [...] das ciências individuais" tenha superado a antiga ontologia europeia, ele pagou este progresso ao preço de que a crítica para diante das ciências individuais, para relegá-las "intocadas e sem correção" a uma racionalidade puramente técnico-instrumental. Com o crescente "domínio" técnico-instrumental dos "detalhes de sua existência social", no entanto, a "totalidade" da "sociedade burguesa" parece ainda mais incontrolável. 
Deste modo, as relações de produção e dominação dadas são isentadas de toda e qualquer crítica, e transformadas em algo "por excelência para ser aceito", em uma facticidade imutável e objetiva (Lukács, 1923, p. 133-134). A filosofia da consciência, em "abstração reflexiva" (Piaget), desenvolveu um conceito universal e igualitário de liberdade e o tomou como base de sua filosofia política e jurídica. Este conceito se revelou como uma contundente "arma de crítica" (Marx) contra o pensamento da velha Europa, focado na ordem, e teve uma contribuição substancial para o sucesso das grandes revoluções constitucionais do século 18. As liberdades de privilégios foram transformadas em direitos universais de liberdade. A legitimidade do mais elevado monarca foi transformada em processos igualitários de legitimação, e o povo tornou-se soberano nos dois papéis: da autoridade constituinte e constituída. Além disso, a soberania popular viabilizada pelo direito foi realizada pela divisão funcional dos três poderes, tornando-se uma "constante da organização" (Festen an Organisation - Hegel) e sendo declarada como sem alternativa (declaração francesa de direitos, art. 16).

Mas ao mesmo tempo o conceito de propriedade privada dos meios de produção separa: o fabricante independente de perucas, do cabeleireiro empregado dependente; a cidadania ativa autodeterminada, do subordinado heterônomo; o senhor branco livre, da natureza escrava negra; a senhoria dos cidadãos do sexo masculino com direitos iguais, do "inimigo interno": as "pessoas comuns" que a confrontam na figura do feminino (Hegel, 1952, p. 140; cf. Wesche, 2014). Já nos primeiros dias da revolução os pregadores jacobinos dos direitos humanos universais ocuparam todas as posições importantes no estado e na sociedade com seus camaradas de classe (Tilly, 1995, p. 195-196; cf. Thornhill, 2011, p. 221; Bellomo, 1995, p. 7-11). Na breve Declaração dos Direitos do Homem e do Cidadão, que de resto não contém uma única palavra supérflua, que faz tudo "o que era sólido e estável" se "esfumar", que "dessacraliza" "tudo o que era sagrado" (Marx e Engels, 1999), um único direito é declarado duas vezes como norma "inviolável e sagrada" de toda e qualquer constituição: a propriedade privada (art. 2 e 17). Na "contradição dialética" entre uma elevada consciência de classe universal e os modestos interesses particularistas de classe burguesa Lukács (1923, p. 73-74) vê um elemento trágico pelo fato que "a luta contra a organização estamental da sociedade tenha sido travada em nome da 'liberdade', que no momento da vitória teve de ser transformada em nova opressão". A "descoberta" de Kant, de acordo com Adorno, "foi progressista: [...] Pelo estabelecimento da unidade racional da vontade como a única autoridade ética", o sujeito humano "ganhou proteção contra a violência cometida contra ele pela sociedade hierárquica 
[...]. A internalização da sociedade como um todo toma o lugar dos reflexos de uma ordem estamental" (Adorno, 1996, p. 237). O livre-arbítrio é "o poder da consciência" com o qual ele deixa a sua própria esfera de influência, mudando assim o que simplesmente é (ibid., p. 240). Mas, precisamente aqui o poder da consciência se defronta com uma antinomia do pensamento burguês: a "aversão burguesa desalentada" de Kant com relação à "anarquia não é menor do que sua vontade burguesa autoconfiante contra o paternalismo. [...] $\mathrm{O}$ fato que Kant pensa liberdade apressadamente como uma lei revela que ele é tão pouco rigoroso com ela quanto sempre o foi sua classe (ibid., p. 248). No final, a "autonomia absoluta da vontade" rebate em forma de "domínio absoluto sobre a natureza interna" (ibid., p. 253).

(3) Embora seja correto que, como afirma John Rawls, seja a mesma igualdade que a Declaração de Independência dos Estados Unidos atribui a todas as pessoas, a qual Lincoln invocou "para condenar a escravidão" e que no século 20 é invocada por aqueles que condenam "a desigualdade e a opressão das mulheres" (Rawls, 1988, p. 27). Mas - e esta é a dupla quintessência da crítica objetiva $e$ social à reificação do universal - que só se pode sabê-lo depois de ter sido feito. Enquanto o postulado da igual liberdade de todos exclui os escravos, as mulheres, trabalhadores empregados e negros [Farbige], esta liberdade permanece para eles uma famigerada abstração que em nome da humanidade lhes rouba sua humanidade. Assim como não existe uma árvore por detrás do tronco, dos galhos e das folhas, assim tampouco há um estado aquém do direito e nenhum direito aquém da multiplicidade de suas leis, regulamentos, decisões e sentenças de execução (Kelsen, 1960, p. 177). A igual liberdade de todos não é uma entidade atemporal, como não o são a verdade ou uma classe de possíveis objetos. Ela somente existe em suas respectivas concretizações legais e normativas e só nelas e não por detrás delas.

\section{4}

Propriedade privada é um conceito jurídico, no qual a indiferença da lei coincide com o poder administrativo do estado e com os imperativos de exploração da economia capitalista, cujo mercado de trabalho advém dos ditames do trabalho morto sobre o trabalho vivo. Pelo fato que a filosofia da consciência e as teorias constitucional e do direito dos séculos 18 e inícios do 19 que a seguiram fundamentarem a propriedade privada no relacionamento de um sujeito de direito com uma coisa e desta relação derivam um direito subjetivo que é prescrito transcendentalmente à ordem objetiva do direito positivo, 
no conceito de propriedade se amalgamam de modo exemplar a reificação do conceito jurídico universal com os interesses de classe da burguesia. A Filosofia do Direito, de Hegel, ainda segue esta ordem das coisas. Assim como as declarações e as teorias do direito dos seus antecessores, Hegel parte do conceito universal de direito ao definir o direito como vontade livre e autorreflexiva $(\S 4,21,27)$, que então é determinado mais precisamente como seu "ser-aí" (Dasein), o que significa, ser definido como sua realidade histórico-social (§ 29). Mas, assim como nos primeiros textos constitucionais e nos seus antecessores, a existência (Dasein) legal da liberdade universal de todos e de cada um se concretiza numa ordem legal válida, cuja "função ideológica" consiste em garantir a manutenção e reprodução da propriedade privada e, portanto, em garantir a acumulação privada do capital e antepor à intervenção plasmadora do legislador uma "barreira intransponível" (Kelsen, 1960, p. 175).

Na medida em que Hegel concretiza como direito privado o "princípio do idealismo", que em termos lógicos consiste na reflexão do sujeito que abstrai negativamente, e em termos jurídicos, na existência do livre-arbítrio, e o unifica com o "princípio da propriedade", "a concepção hegeliana perde o seu conteúdo crítico e, finalmente, serve a uma justificação metafísica da propriedade privada" (Marcuse, 1962, p. 170). O idealismo, que (como uma teoria crítica) consiste unicamente em não absolutizar "as coisas", em considerá-las "não como elas são, em si para e para si”, fixas, mas mutáveis ( $\$ 44$, adendo) - ou, como afirma Adorno, mudar com o poder da consciência aquilo que meramente é (ver item 3, acima) - absolutiza justamente a instituição da propriedade privada. Assim como o platônico faz com o universal, Hegel desvincula a propriedade de "qualquer contexto aleatório" e a "hipostasia como uma relação ontológica" (ibid., p. 174). Assim, a propriedade privada, juntamente com as condições desiguais de sua produção e distribuição, tornase a medida efetiva da liberdade legal: a unidade da reificação conceitual com a dominação social.

A igual liberdade de todos se converte em sua reificação não apenas conceitualmente, mas também na vida real: "A pessoa é subsumida em sua propriedade e é pessoa apenas devido à sua propriedade" (ibid., p. 175). A propriedade da própria força de trabalho é subjugada ao imperativo da exploração do trabalho morto (capital constante e variável) e, como Hegel já havia claramente reconhecido, o tempo de vida transformado em trabalho alienado, excetuado apenas o resto minimamente necessário para a reprodução da vida material, espiritual e legal: "Das minhas aptidões particulares [...] eu posso [...] vender um uso limitado no tempo para outrem. Com a venda 
de todo o meu tempo, concretizado através de trabalho, [...] eu [...] tornaria a minha personalidade em propriedade de outrem" (§ 67). A passagem da escravidão para o trabalho livre assalariado é, de fato, um "grande progresso" na "emancipação política", mas nenhum na emancipação "humana" (Marx, 1976, p. 356, 370). Na história real, tão logo os portões da fábrica se fecham às costas dos trabalhadores livres, a escravidão passa a ser modelo para o trabalho assalariado (Marx, 1969, p. 190-191; Buck-Mors, 2009).

A liberdade objetivada na propriedade consolida a barreira do direito subjetivo face ao direito objetivo como uma barreira de classe contra a emancipação política do ser humano e do cidadão. Como Hegel constata de modo sóbrio e materialista, a propriedade é a "base da desigualdade" (§ 49) que faz restar da igualdade apenas um direito formulado no modo no subjuntivo, que "cada pessoa deveria ter propriedade", contentando-se de resto com a indiferença do direito "contra a especificidade" ( $§ 49$, adendo). Enquanto a emancipação política na forma da universalidade da lei, igualmente válida para todos é progressiva, sua concretização jurídica é regressiva para a essência humana do indivíduo, porquanto sua particularidade - o não-idêntico de Adorno - é indiferenciada sob o domínio da propriedade privada e da acumulação privada de capital, e subjugada às abstrações reais do poder administrativo, do direito técnico e da exploração econômica. ${ }^{4}$ Mais que isto: sob o domínio da propriedade privada, a emancipação política bloqueia a emancipação humana rumo a um "mundo" de "pessoas verdadeiramente individuais", que pudessem autodeterminar-se em sua "vida empírica", seu "trabalho individual" e suas "circunstâncias individuais" (Marx, 1976, p. 370). Somente a libertação da dominação da propriedade privada, da acumulação privada de capital e de sua ditadura do tempo afirmariam igualmente o "valor peculiar" do "mundo humano e da natureza" (ibid., p. 375-376), sim, até mesmo das "pessoas como adeptas de uma religião em particular", em "sua vida verdadeiramente individual” (ibid., p. 355).

Naquela época, em 1844, Marx dá apenas um, mas bem significativo exemplo da diferença entre emancipação política e humana. O limiar para a emancipação humana, segundo seu argumento em A sagrada família, seria transposto justamente quando o "sábado judaico" tivesse "o mesmo direito" a ser um feriado legal como o domingo cristão, que a maioria parlamentar cristã teria logrado aprovar na França politicamente emancipada alguns anos antes (Marx e Engels, 1990, p. 44). Só então haveria "a mesma igualdade” (Rawls)

\footnotetext{
${ }^{4}$ Marcuse (1962, p. 175); sobre o ambíguo conceito de Gleichgültigkeit cf. Theunissen (1980, p. 433-471). N.t.: o autor faz um jogo de palavras entre a liberdade e o direito igualmente válidos (gleich gültig) e os efeitos de indiferenciação/indiferença (gleichgültig).
} 
da constituição francesa, que faria justiça tanto à especificidade do domingo cristão como à do sabatt judaico. ${ }^{5}$ Mas ações afirmativas e normas contra discriminação que traduzissem (ainda que inadequadamente) em conceitos jurídicos o desejo de emancipação humana de fazer justiça às circunstâncias especiais de vida em cada caso, não havia na sociedade do século 19, que ainda era completamente burguesa na sua natureza de classe.

Outro exemplo importante da emancipação humana encontra-se no primeiro volume de $O$ capital. Ele diz respeito à limitação legal da jornada de trabalho, pela qual a "coerção" do trabalho assalariado, de "vender voluntariamente a si próprio", é afrouxada e uma parte da "propriedade individual" de tempo livremente disponivel, que Marx distingue da propriedade privada, é "reestabelecida". ${ }^{6} \mathrm{O}$ exemplo da bem-sucedida luta pela jornada normal de trabalho na Inglaterra, de 1833-1864, mostra que o bloqueio da emancipação humana pode ser superado politicamente pelo medium da emancipação política - através da luta pública de classe, da associação sindical e de legislação parlamentar -, que a dialética negativa deste grande progresso pode ser corrigida através daquele medium e recuperada face ao imperativo capitalista do tempo. Em lugar da "ostentação de um catálogo (subjetivo-legal) de "direitos humanos inalienáveis" "que encarnam o progresso da emancipação política, mas blindam seu núcleo econômico, a acumulação privada de capital, da intervenção plasmadora do legislador, "passa a valer a humilde Magna Charta (objetiva-legal) de uma jornada de trabalho legalmente limitada" que traz mais progresso, o primeiro passo politicamente conquistado rumo à emancipação humana, e com isso abre as portas para uma reinterpretação radical dos direitos humanos - seja ela reformista ou revolucionária. "Quantum mutatus ab illo!" (Marx, 1969, p. 320; cf. Çidam, 2012).

A crítica à injustiça social da dominação de classe e à especificidade por ela oprimida nestes exemplos não visa à correção do resultado em termos de bens desigualmente distribuídos, mas à revogação das condições desiguais e injustas de produção da dominação social (ver item 2, acima).

\section{5}

Com relação a seus pressupostos, a filosofia hegeliana do direito não se limita ao direito subjetivo "abstrato", mas acolhe-os todos passo a passo, para superá-los na totalidade ética de estado razoável. ${ }^{7}$ Assim se pretende

${ }^{5}$ Sobre o conceito de especificidade é esclarecedor o livro de Hindrichs (2015).

${ }^{6}$ Marx (1969, p. 294-320, 791, 793); sobre o critério relativo ao tempo disponível, cf. Marx (1953, p. 594, 596); Marx (1968, v. 3, p. 252-253).

7 Com relação à figura dialética central do pensamento de acolher pressupostos, cf. Bubner (1973). 
que as limitações da respectiva forma anterior sejam negadas e superadas, o abstrato seja concretizado e a razão seja realizada. Mas o acolhimento superador dos pressupostos através de uma teoria crítica e negativa do direito e da sociedade na filosofia do direito de Hegel termina numa afirmação plena da dominação da propriedade privada e de sua transfiguração na eticidade substantiva da sociedade burguesa. Os direitos humanos, cujo valor de face em 1820, quando as Linhas fundamentais da filosofia do direito foram publicadas, esgotavam-se nos direitos subjetivos da propriedade privada (ver item 3, acima), demarcavam os limites da constituição legal do sistema de necessidades ( $§$ 209). Hegel descreve este sistema como um sistema econômico funcionalmente diferenciado, capitalista ( $§ 198-200)$, que não consegue controlar seus "perigosos espasmos", "colisões" de "interesses" (§ 236) e “o excesso de pobreza e de procriação do populacho" (§ 245) (cf. Ruda, 2011). Os direitos humanos subjetivos, que são "de infinita importância" para a emancipação política da sociedade burguesa apolítica e para a liberdade de circulação de mercadorias, imunizam, no entanto, ao mesmo tempo o sempre expansivo e cada vez mais concentrado sistema da propriedade privada (§ 244) contra o acesso plasmador do poder legislador. O direito humano torna-se "deficiente" no momento em que "como cosmopolitismo" levanta a pretensão de "enfrentar" a "vida concreta do estado" e sua limitação pelo direito subjetivo da propriedade privada ( $\$ 209)$.

Embora para Hegel o sistema de acumulação privada de capital seja um "sistema da [...] eticidade perdida" (§ 184), um "espetáculo [...] da perversão ética" ( $§ 185)$, mera "aparência de razoabilidade" (§ 189) gerado historicamente ("espiritualmente") de um "resíduo do estado de natureza" que "não apenas não supera [...] a desigualdade entre os humanos [...] dada por natureza [...] mas a produz" e multiplica "a partir do espírito" (§ 200). Mas também a subordinação do "estado de emergência e de entendimento" (§ 183) da sociedade burguesa (os sistemas econômico e jurídico, a corporação e a polícia) à razão maior do estado constitucional autônomo continua comprometida com o objetivo de garantir a autopreservação da sociedade burguesa e de sua instituição principal, de transfigurar o "paládio do estado ético, a propriedade" (Heine) e protegê-lo contra ataques do populacho, da opinião pública e dos legisladores.

Se bem que Hegel defina a liberdade objetivada no direito subjetivo à propriedade privada como sua "primeira" ainda "deficiente realidade" ( $\$ 41$, adendo) e supere (aufheben) este pressuposto na liberdade política do indivíduo (mesmo que concretizada restritivamente) de decidir sobre as leis de que seja destinatário, ele restringe a legislação desde logo ao objetivo 
de realizar "a proteção da propriedade através da administração da justiça" (§ 208) (cf. Marcuse, 1962, p. 181, 187-188). O direito subjetivo à liberdade acaba por revelar-se para Hegel como "barreira intransponível" (Kelsen) contra o "domínio" político-legal "dos dominados" (cf. Möllers, 1997, p. 97). $\mathrm{O}$ acolhimento deste pressuposto, que entrelaça o direito com a base econômica da sociedade, falha: o sistema da propriedade privada continua a ser o centro e a base da filosofia do direito, sua barreira de classe.

Esta, no entanto, de forma alguma é a última palavra da teoria social dialética de Hegel, porquanto já no capítulo final sobre o direito internacional ele relativiza o direito do estado $e$ da sociedade com base no direito do espírito cosmopolita (Weltgeist) (cf. Fine, 2003). A relativização torna-se ainda mais clara quando Hegel refere as pretensões de verdade do estado, respectivamente, do espírito objetivo, às formas, às esferas de valor (Weber) ou aos subsistemas (Parsons) do espírito absoluto, a religião, arte e ciência, para expor o espírito objetivo ao "tremendo poder do negativo" que está encarnado nas formas do absoluto. ${ }^{8}$ Avaliado em termos dos conceitos de liberdade, igualdade e razão do espírito absoluto, não só o estado burguês da propriedade privada dos meios de produção, mas o estado em si é considerado demasiado insuficiente e desmistificado como um mero episódio no oceano da história universal (cf. Marcuse, 1962, p. 161-162, 181-183, 198-199). Os conceitos fundamentais de liberdade e razão, que subjazem ao espírito objetivo e que estabelecem conexões - mutuamente relativizadoras - com o espírito absoluto, eles mesmos não devem ser reificados como uma entidade atemporal ou como uma substancialidade que subsiste a despeito de todas as mudanças. Tão somente ali onde elas forem efetivamente realizadas como negação de suas limitadas concretizações, a razão, a liberdade e a igualdade das declarações de direitos do século 18 subsistem como a mesma que foi reivindicada tão somente na crítica social à propriedade privada e depois na crítica feminista à opressão das mulheres.

A interpretação que Herbert Marcuse faz da Filosofia do direito de Hegel é interessante porque ela credita o fechamento afirmativo desta filosofia não apenas ao entendimento materialista e resignado de Hegel da superioridade factual da base social, ${ }^{9}$ mas, como Kelsen e outros críticos da reificação do

\footnotetext{
${ }^{8}$ Cf. Hegel (1955, p. 29). Sobre o papel da relativização de todas as substancializações em Hegel, ver Larmore, Charles (2014, p. 151).

9 'Hegel sabia que 'uma forma de vida' havia envelhecido e que ela nunca poderia ser rejuvenescida pela filosofia. As últimas seções do prefácio caracterizam o tom de toda a Filosofia do direito. Elas expressam a resignação de um homem que sabe que o fim da verdade representada por ele era iminente e que ela não poderia mais animar o mundo" (Marcuse, 1962, p. 165-166).
} 
universal, credita-o também à hipostasia conceitual das relações jurídicas aleatórias, históricas e intersubjetivas entre pessoas como uma relação ontológica entre o sujeito e as coisas (Marcuse, 1962, p. 173, n. 2 e p. 174). O próprio Hegel por isso já oscilava entre a reificação da propriedade como um pressuposto - ontológico imutável, fundado na relação natural e jusnatural da pessoa com uma coisa - de todo direito positivo, realizada nas Linhas fundamentais da filosofia do direito, e uma compreensão (exposta na Jenenser Realphilosophie e na Fenomenologia do espirito) da propriedade privada como uma relação entre pessoas, que pode ser precisada e mudada legalmente.

Exatamente este é o ponto em que não apenas incide (1) a crítica marxista às condições desiguais de produção da riqueza social caracterizadas pela dominação apolítica do capital sobre o trabalho ("exploração"), mas também (2) a crítica de Kelsen às condições desiguais de produção do direito positivo caracterizadas pela dominação política de um bloco de poder político-econômico sobre a cidadania. As duas críticas estão numa relação complementar antes que em competição. Elas se contradizem apenas quando, como no marxismo ortodoxo, esta (cidadania) é reduzida àquele (bloco de poder). ${ }^{10}$

(1) A crítica às relações de produção responde à injustiça das condições desiguais de produção da riqueza social com a fórmula da socialização dos meios de produção. A "base econômica" (Marx) também em Rawls (2003, p. 210ss) faz parte da basic structure de instituições justas. Trata-se de "alternativas ao capitalismo" que devem garantir "o acesso equitativo (fair) a processos equitativos" já que o capitalismo laissez-faire "assegura unicamente a igualdade formal e rejeita tanto o valor equitativo das iguais liberdades políticas como também a igualdade equitativa de oportunidades" (Rawls 2003, p. 211, 214). A igualdade equitativa de oportunidades é definida por Rawls em Uma teoria da justiça (1979, p. 86; cf. 2014) como igualdade democrática pela combinação das duas dimensões, a saber, "vantagem para todos" (princípio da diferença) e "acessível a todos" (igualdade de oportunidades), e claramente diferenciada da igualdade liberal do capitalismo laissez-faire (liberdade política contra neoliberalismo). A fim de possibilitar a igualdade democrática, as condições estruturais iniciais da justiça distributiva devem ser constituídas no mínimo de modo que "mercados livres [...] sejam inseridos em instituições

\footnotetext{
${ }^{10}$ Uma crítica certeira se encontra em Kelsen (1967).
} 
políticas e legais que regulam todo o fluxo econômico e mantêm as relações sociais que são necessárias para a igualdade equitativa de oportunidades" (1979, p. 93).

Estas condições iniciais da economia da sociedade, cuja função é a adaptação da sociedade ao seu ambiente natural ("adaptive system" segundo Parsons), também incluem sua "base natural" (Marx), em particular o organismo humano. A loteria da natureza que (como em Hegel) não é justa nem injusta, mas a partir da perspectiva de atores sempre já socializados é arbitrária e, portanto, (ao contrário do horizonte conceitual burguês de Hegel) relevante para questões de justiça, necessita ser equilibrada compensatoriamente (Rawls, 1979, p. 94, 121ss). "Justa ou injusta é a maneira como as instituições se comportam diante deste fato." A basic structure da sociedade assume a "arbitrariedade da natureza". Mas as pessoas não precisam submeter-se a "essas casualidades [...]. O sistema social não é um ordenamento imutável para as pessoas, mas um padrão humano para o agir" (ibid., p. 123). Por isso aquele que "é favorecido pela natureza, seja ele quem for [...] só pode deliciarse dos seus frutos até o ponto em que isso também melhora a situação dos desfavorecidos" (ibid., p. 122).

A crítica às condições desiguais e injustas de produção da riqueza não atinge apenas o capitalismo laissez-faire, mas também o recentemente transfigurado "capitalismo de bem-estar" (New Deal, Capitalismo Renano, Sistema Beveridge, Folkhemmet), que distribui a riqueza de forma mais justa, ou, pelo menos, que deixa sobrar mais em baixo, mas mina tecnocraticamente a democracia, o que se manifesta então em crises de motivação, crises estruturais e problemas de legitimidade (Offe, 1972; Habermas, 1967; 1973; cf. Marcuse, 1964; e espec. Marcuse, 1970). A remodelagem tecnocrática das instituições democráticas levou àquilo que a "affirmative action" seguiu sendo determinada por "white" e masculino, apesar da oposição de um direito eleitoral inclusivo (Katznelson, 2005). O capitalismo do estado de bem-estar é um caso exemplar de injustiça estrutural de uma justiça distributiva puramente orientada para os resultados. Nas condições de partida da produção, o poder e a impotência, a autodeterminação e a heteronomia estão distribuídos muito desigualmente, porquanto o capitalismo do estado de bem-estar ainda permite um "alto grau de desigualdade em termos de propriedade de bens reais (meios de produção e recursos naturais), de modo que [especialmente no lado da entrada do sistema] a gestão da economia e uma grande parte da vida política estão nas mãos de poucos" (Rawls, 2003, p. 214-215). Algo similar vale, de modo muito agravado, para o sistema soviético do socialismo burocrático com sua economia planificada, não emprestada a Marx, mas ao czarismo (ibid., p. 215). 
Com uma teoria da justiça mais exigente da igualdade democrática coadunam melhor meios de produção socializados, ou seja, o socialismo "liberal" ou "democrático" (ibid., p. 212). Embora, de acordo com Rawls, a igualdade democrática - segundo o modelo rousseauniano - também seria compatível com uma forma de propriedade privada dos meios de produção que proibisse toda forma de exploração do trabalho vivo pela acumulação privada de capital, que segue a "lei natural" da sociedade burguesa, segundo a qual "a proporção de capital, o lucro, [... cresce] na mesma proporção que a proporção do trabalho, o salário, cai” (Marx, 1973, p. 314; Rawls, 2003, 216217). Este modelo - e nisso Rousseau estava certo - funcionou provavelmente por centenas de milhares de anos em sociedades simples, segmentárias. Mas, mesmo desconsiderando-se o fato que ele dificilmente seria compatível com noções modernas de autodeterminação individual e coletiva, muito menos com as condições de socialização pós-tradicionais e individualizadas necessárias para elas, o modelo simplesmente não é complexo o suficiente e, na sociedade mundial e funcionalmente diferenciada, aplicável apenas em pequenos grupos e em sistemas de interação simples, mas não em organismos ou sistemas funcionais complexos.

Resta então apenas um socialismo democrático que não interfira na lógica própria do sistema econômico e do mecanismo técnico de informação dos mercados livres, pelo menos de mercados consumidores livres. Num sistema assim, do qual modelos bem funcionais de cogestão dos trabalhadores já se aproximam, “os meios de produção pertencem à sociedade", enquanto “a gestão e a administração, por exemplo, são eleitos pelos respectivos trabalhadores, caso não estejam diretamente em suas mãos” (Rawls, 2003, p. 215). Exatamente assim como atualmente o direito fundamental (exigível judicialmente) de propriedade em países como a República Federal da Alemanha já está concebido pelo legislador de tal modo que apenas a propriedade pessoal é constitucionalmente protegida, mas não a propriedade privada dos meios de produção; o pressuposto mais importante de Rawls, a separação destas duas formas de propriedade no nível constitucional, há muito tempo não é mais uma utopia (Rawls, 2003, p. 180, 216; sobre a Alemanha: Denninger, 1984, p. 817). Excluídos da forte proteção dos direitos constitucionais e, portanto, socializáveis a qualquer momento, seriam especialmente a propriedade privada "de recursos naturais e de meios de produção, incluindo o direito à aquisição e à herança" (Rawls, 2003, p. 180). Rawls certamente tem razão quando diz que o socialismo democrático, que é compatível com um ordenamento econômico não mais capitalista, mas igualmente funcional, diferenciado e, portanto, eficaz, não fracassou na extrapolação utópica da 
ideia, mas falhou porque a ideia de "empresas geridas por trabalhadores" até o momento "não teve uma oportunidade equitativa" na sociedade capitalista de classes. A ela se opõem sobretudo poderosos interesses de classe. Mas mesmo que tenhamos de conviver com os imperativos sistêmicos de uma economia mundial diferenciada enquanto não existirem equivalentes funcionais eficazes, os interesses das classes hoje internacionalmente dominantes que deles se beneficiam não são um imperativo sistêmico.

(2) Pelo menos juridicamente, tanto no direito constitucional nacional como internacional não há mais obstáculos significativos a uma transição do estado de bem-estar tecnocrático para o socialismo democrático. Assim, por exemplo, o legislador da constituição alemã (Grundgesetz) se vincula (Art. 20, §; Art. 146) à efetivação dos princípios do estado de bem-estar social no artigo 3, $\S 1$ (igualdade perante a lei) em conjunto com o Art. 20, §1 (estado [...] social"), Art. 23, 11 (vinculação da transferência de direitos de soberania aos princípios sociais) e Art. $28, \S 1$ ("estado social de direito"). ${ }^{11}$ A constituição alemã prescreve explicitamente que "tudo, inclusive a ordem econômica, pode tornar-se tema da política", ou seja, pode ser objeto da legislação parlamentar. Um "conteúdo da propriedade absoluto, fixo, por assim dizer exigido pela 'lógica do estado de direito' [...] não existe". De acordo com aquela constituição, explicitamente o direito à propriedade deve "manter-se aberto para desenvolvimentos legislativos posteriores" (Denninger, 1984, p. $815,839 \mathrm{ss})$.

Isso nos traz à questão crucial sobre as condições igualitárias de produção da dominação política. Somente se estas forem autodeterminadas, ou seja: se elas se originarem da dominação igualitária dos dominados, ideias alternativas sobre a organização econômica e a diferenciação social podem ser discutidas e decididas de modo tal que façam justiça a cada subjugado e subjugada às leis em suas circunstâncias particulares de vida. Somente desta maneira, através de uma democracia radical, poderia ser assegurado que a justiça de resultado (bastante secundária), se ela se materializar, não seja novamente anulada por condições desiguais e injustas de possibilidade e de partida. Aqui retorna novamente o velho problema do poder legislativo constituinte permanente, que deveria ser capaz de gerar ele próprio as condições sociais, políticas, culturais e econômicas de seu exercício (cf. Niesen, 2014).

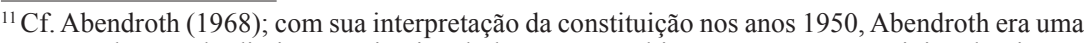
voz no deserto do direito constitucional alemão, mas ultimamente esta é a opinião dominante (cf. Möllers, 2000, p. 14).
} 
Embora os pré-requisitos legais para a autodeterminação democrática organizada pela via parlamentar ainda estejam dadas, trinta anos de dominação global da episteme neoliberal e a inversão das relações de dependência entre o mercado mundial e o universo nacionalmente fragmentado de estados em favor dos mercados e dos investidores levaram a que a democracia esteja pressionada em todos os lugares e tenha regredido mais e mais ao status de um direito constitucional simbólico. ${ }^{12}$ Com o retorno factual às condições de diferenciação social do final do século 19 - a ascensão da curva $U$ descrita por Colin Crouch desde os anos 1980 -, o sistema legal adquire de novo a condição de ser uma barreira intransponivel para a reconfiguração material do direito à propriedade e do direito patrimonial.

Após trinta anos de ataques ao estado e aos impostos e da simultaneamente crescente aceitação e autoridade de tribunais e tribunais superiores, nacionais e transnacionais, amplamente desvinculados da legislação parlamentar, consolidou-se novamente no discurso público a ideologia adequada a esta facticidade, segundo a qual liberdade seja única e exclusivamente autonomia privada e que a legislação ainda democrática não passe de uma dominação alienígena. $\mathrm{O}$ velho dualismo liberal entre direito subjetivo à liberdade e direito coercitivo objetivo parece determinar novamente a interpretação pública relativa ao direito - e não só a dos presidentes emprestados junto ao Banco Mundial ou à República Democrática Alemã, ou na província da Baviera, entre Prantl e Hoeneß. ${ }^{13}$ Quem sonega 30 milhões de euros em impostos pode ir à prisão sob os aplausos públicos efusivos de seus companheiros, que alguns dias antes haviam sido flagrados na alfândega com dois relógios Rolex no mesmo braço, saudado como um combatente íntegro da liberdade, porque está respaldado pela rediviva ideologia segundo a qual seu direito à propriedade advém de sua relação puramente individual com uma coisa, mesmo se a coisa não seja um relógio Rolex, mas dinheiro ontologicamente volátil que nunca será impresso,

\footnotetext{
${ }^{12}$ Sobre o constitucionalismo simbólico, veja o estudo de caso de Marcelo Neves (1992).

${ }^{13}$ N.t.: O autor parece se referir a Horst Köhler, presidente da Alemanha entre 2004 e 2010 e antes disto presidente do Fundo Monetário Internacional (e não do Banco Mundial); teve que renunciar em 2010, após admitir em entrevista que a Alemanha intervinha militarmente no Afeganistão também por interesses econômicos; a Joachim Gauk, um pastor protestante e militante dos direitos humanos na antiga DDR, hoje presidente da Alemanha. No sui generis e orgulhoso estado da Baviera, Heribert Prantl é advogado e jornalista liberal, chefe de redação do Süddeutsche Zeitung e se notabilizou por polêmicas por um jornalismo de discutível profissionalismo; Uli Hoene $\beta$, ex-todo-poderoso presidente do clube de futebol Bayern, atualmente preso por sonegação de impostos. A menção aos relógios Rolex, logo a seguir, se refere provavelmente a Karl-Heinz Rummenigge, sucessor de Hoeneß na presidência do clube Bayern, flagrado pela alfândega com os dois relógios não declarados ao retornar do Qatar e, posteriormente, condenado a pagar 250.000 euros pela sonegação de impostos. O estado da Baviera é governado desde o final da Segunda Guerra por uma elite político-empresarial conservadora que se declara ostensivamente ciosa dos valores católico-cristãos.
} 
nunca será passível de ser manipulado. Hoeneß pensa como o teórico jurista burguês na apropriada descrição de Kelsen (1967, p. 105): "Primeiro surgem direitos subjetivos (por exemplo na forma de apropriação original - de dois relógios Rolex ou de uma fábrica de salsicha - HB) e só mais tarde o direito objetivo é acrescido ao direito subjetivo individual surgido independentemente como ordenamento estatal protegendo, reconhecendo, garantindo". Se este ordenamento não puder mais protegê-lo e ele for molestado pelos fiscais da Receita ou da aduana, o presidente antigo e novo do clube de futebol está novamente, como em Hobbes, no estado de natureza, e toda a história do individualismo possessivo pode começar do zero, com o portador dos relógios Rolex de direitos subjetivos como "guardião da liberdade condicional": "Eu cometi um erro. [...] A justiça fez o seu trabalho [...]. Quando eu estiver de volta, não vou me aposentar. A minha carreira não terminou por aqui". ${ }^{14}$

Quando esta ideologia ainda era um direito consolidado, Kelsen (1960, p. 174) a execrou. O "assim chamado direito civil" é, na melhor das hipóteses, "autonomia em um sentido muito limitado e impróprio", porquanto ninguém pode "conceder direitos a si próprio"; primeiro, porque isso só é possível entre pelo menos duas pessoas - com Habermas (1992, p. 306) pode-se dizer: "socializadas horizontalmente" - e, segundo, essas pessoas só podem fazer um contrato válido se os requisitos legais objetivos estiverem dados (Kelsen, 1967, p. 175). "A função ideológica de toda essa [...] definição conceitual do sujeito de direito [...] é fácil de reconhecer: é necessário preservar como válida a noção de que a existência [...] da propriedade privada é uma categoria transcendental face ao direito objetivo, positivado, criado por seres humanos e passível de ser modificado"; a propriedade privada é uma instituição, no sentido dado por Gehlen, "frente à qual o regramento do conteúdo do ordenamento jurídico encontra uma barreira intransponível". O conceito de um direito subjetivo imutável pela via objetivo-legal torna-se "tão importante" como ideologia quanto mais o ordenamento jurídico que garante "a instituição da propriedade privada" é reconhecido "como um ordenamento mutável, em constante mudança, criado pelo capricho humano e que não repousa na vontade eterna da divindade, na razão ou na natureza: especialmente quando a produção desse ordenamento resulta de um processo democrático". ${ }^{15}$

\footnotetext{
${ }^{14} \mathrm{Cf}$. bild.de: Hoeneß kündigt Rückkehr an <www.bild.de/sport/fussball/uli-hoeness/ich-habehass-in-mir-entdeckt-35797196.bild.html > - onde o ex-presidente preso anuncia que concorrerá novamente à presidência do clube Bayern .

${ }^{15}$ Kelsen (1967, p. 175); observe-se a coincidência com Marx (1969, p. 16), para quem a sociedade moderna não é "um cristal sólido, mas um organismo mutável que se encontra em permanente processo de mutação".
} 
Este texto foi publicado por Kelsen em 1934. Somente após a Segunda Guerra Mundial a democracia de massas, organizada de modo parlamentar, igualitário e crescentemente inclusiva prevaleceu passo a passo, começado a suspender a proteção privilegiada da instituição da propriedade privada. Historicamente isto levou à formação do estado de bem-estar democráticocapitalista, deformado tecnocraticamente. Na década de 1960 começou uma ampla reforma das suas instituições que visava à formação alternativa de um socialismo democrático que se orientava pela igualdade das circunstâncias vivenciais específicas. Estas reformas, que em certos aspectos (como, por exemplo, na legislação sobre direitos de cidadania nos Estados Unidos) foram bem-sucedidas, não eram, como a ideologia liberal muitas vezes insinua, obra dos tribunais, mas da mesma forma como as reformas sociais radicais anteriores; elas eram fruto da legislação parlamentar impulsionada por discussões e pedradas (Pflastersteinen = paralelepípedos), por conflitos públicos e por lutas por inclusão ampla (Wright, 2014; Katznelson, 2014, p. 58-60).

Mas as reformas fracassaram no final de 1970 face à contínua resistência das classes dominantes, que não haviam se tornado mais fracas, porém mais fortes com o impopular estado de bem-estar; gratamente elas recorreram à ideologia seletivamente bem-sucedida do neoliberalismo que num nicho evolutivo e muito ativo sobreviveu à "injustiça" da crescente igualdade e do declínio dos lucros, à espera da oportunidade para valer-se dos problemas estruturais e de legitimação que ocorreram na década de 1970, e assim reconquistar a hegemonia cultural do liberalismo com um pelotão treinando no Mont Pelerin. ${ }^{16}$ Mas, ao contrário do longo período do primeiro ápice da curva em U, voltou a ideologia, mas não o sólido direito liberal dos direitos subjetivos imutáveis. A estrutura legal e constitucional - more or less, e apesar do corte de direitos de bem-estar - se manteve programada com orientação para o socialismo democrático. Mas ela foi induzida a uma dormência similar ao coma; na aplicação concreta da lei, a estrutura legal foi substituída por uma ordem concreta de regimes jurídicos, o managerial mindset, técnico-instrumental, programada com vistas à efetividade, "flexível e elástica" (Carl Schmitt), não baseada em direito explícito. Sob a nova bandeira da "governance" ela gera legitimidade sem legalidade, constrói programas de recuperação econômica e regimes de segurança, zonas especiais de processamento de exportações e zonas especiais de tortura, tudo a serviço do já bem avançado

\footnotetext{
${ }^{16}$ N.t.: referência à Sociedade Mont Pèlerin, fundada por Hayek, renomada por ser um bastião do neoliberalismo.
} 
projeto de transformar nações, federações transnacionais e organizações internacionais, tudo enfim, especialmente as universidades, em empresas. Se a teoria segundo a qual as sociedades não são capazes de se reproduzirem sem uma referência intrínseca e séria (e não apenas instrumentalmente lúdica) à verdade, à razão e à liberdade igualitária estiver correta, é certo que esta via não terminará bem. $\mathrm{O}$ direito por ora induzido a uma dormência profunda quando trazido de volta ao estado de vigília poderia contra-atacar. Então parecem haver apenas duas alternativas: a regressão etno-racista abaixo do nível da solidariedade nacional - ou a transnacionalização do socialismo democrático.

\section{Referências}

ABENDROTH, Wolfgang. Zum Begriff des demokratischen und sozialen Rechtsstaats im Grundgesetz der Bundesrepublik Deutschland. In: Ernst Forsthoff (org.). Rechtsstaatlichkeit und Sozialstaatlichkeit. Darmstadt: Wissenschaftliche Buchgesellschaft, 1968 [1954]. p. 114-144.

ADORNO, Theodor W. Negative Dialektik. Frankfurt am Main: Suhrkamp, 1966 [Dialética negativa. Rio de Janeiro: Zahar, 2009].

APEL, Karl-Otto. Transformation der Philosophie. Frankfurt am Main: Suhrkamp, 1973. $2 \mathrm{~V}$.

APEL, Karl-Otto. Paradigmen der Ersten Philosophie. Berlin: Suhrkamp, 2011.

BELLOMO, Manlio. The common legal past of Europe 1000-1800. Washington: The Catholic University of America Press, 1995.

BOFINGER, Peter; HABERMAS, Jürgen; NIDA-RÜMELIN, Julian. Einspruch gegen die Fassadendemokratie. Frankfurter Allgemeinen Zeitung, v. 180, 4. Aug. 2012, p. 33 .

$B U B N E R$, Rüdiger. Logik und Kapital: zur Methode einer Kritik der politischen Ökonomie. In: Rüdiger Bubner. Dialektik und Wissenschaft. Frankfurt am Main: Suhrkamp, 1973. p. 44-88.

BUCK-MORSS, Susan. Hegel, Haiti, and universal history. Pittsburg: University of Pittsburg Press, 2009.

ÇIDAM, Volkan. Geschichtserzählung im Kapital. Baden-Baden: Nomos, 2012.

CROUCH, Colin. Post-democracy. Cambridge: Polity, 2004.

CROUCH, Colin. The strange non-death of neoliberalism. Oxford: Polity, 2011.

DENNINGER, Erhard. Von der bürgerlichen Eigentumsgesellschaft zum demokratischen Rechtsstaat. In: Karl-Otto Apel; Dietrich Böhler; Karl-Heinz Rebel (orgs.). Funkkolleg Praktische Philosophie/Ethik. Studientexte. v. 3, Weinheim: Beltz, 1984. p. 814-844.

DEWEY, John. The public and its problems: the later works 1925-1953. Carbondale: Southern Illinois Univ. Press, 1984 [1927]. 
FINE. Robert. Kant's theory of cosmopolitanism and Hegel's critique. Philosophy and social criticism [org. by David Rasmussen], v. 29, n. 6, p. 609-630, 2003.

FORST, Rainer. Transnational justice and democracy: overcoming three dogmas of political theory. Manuscrito apresentado no Constellations 20th Anniversary Conference. New York: New School for Social Research, 26 abr. 2014.

HABERMAS, Jürgen. Technik und Wissenschaft als Ideologie. Frankfurt am Main: Suhrkamp, 1967 [Técnica e ciência como ideologia. São Paulo: Editora Unesp, 2014].

HABERMAS, Jürgen. Legitimationsprobleme im Spätkapitalismus. Frankfurt am Main: Suhrkamp, 1973.

HABERMAS, Jürgen. Die Philosophie als Platzhalter und Interpret. In: Dieter Henrich (org.). Kant oder Hegel? Stuttgart: Klett-Cotta, 1983 [In: Consciência moral e agir comunicativo. Rio de Janeiro: Tempo Brasileiro, 1986. p. 17-35].

HABERMAS, Jürgen. Faktizität und Geltung: Beiträge zur Diskurstheorie des Rechts und des demokratischen Rechtsstaats. Frankfurt am Main: Suhrkamp, 1992 [Direito e democracia. Rio de Janeiro: 1997].

HEGEL, Georg W. F. Phänomenologie des Geistes. Hamburg: Meiner, 1952 [Fenomenologia do espírito. Petrópolis: Vozes].

HEGEL, Georg W. F. Grundlinien der Philosophie des Rechts. Frankfurt am Main: Suhrkamp, 1970 [Linhas fundamentais da filosofia do direito ou direito natural e ciência do estado em compêndio. São Paulo: Loyola, 2010].

HINDRICHS, Gunnar. Schöne Seelen: Schiller, Jacobi, Hegel. In: Thomas Hanke; Thomas M. Schmidt (orgs.). Der Frankfurter Hegel in seinem Kontext. Frankfurt am Main: Klostermann, 2014. p. 161-192.

KATZNELSON, Ira. When affirmative action was white: an untold history of racial inequality in twentieth-century America. New York: W. W. Norton, 2005.

KATZNELSON, Ira. The great and grudging transformation. New York Review of Books, v. 6, p. 58-60, 2014.

KELSEN, Hans. Das Problem der Souveränität und die Theorie des Völkerrechts. Aalen: Scientia, 1981 [1920].

KELSEN, Hans. Reine Rechtslehre. 2. ed. revisada. Wien: Deutike, 1960 [orig. 1934] [Teoria pura do direito. São Paulo, Martins Fontes].

KELSEN, Hans. Allgemeine Rechtslehre im Lichte materialistischer Geschichtsauffassung. In: Hans Kelsen. Demokratie und Sozialismus: Ausgewählte Aufsätze. Vienna: Verlag der Wiener Volksbuchhandlung, 1967. p. 69-136 [orig. Archiv für Sozialwissenschaft und Sozialpolitik, v. 66, p. 449-521, 1931].

KREIDE, Regina. Globale Gerechtigkeit und Politische Praxis. Frankfurt am Main: Campus, 2013.

KREIDE, Regina. Globale Politik und Menschenrechte: Macht und Ohnmacht eines politischen Instruments. Manuscrito. 2013a.

KRUGMAN, Paul. The timidity trap. New York Times, March 21, 2014, p. A23. 
LARMORE, Charles. Review of Axel Honneth, Das Recht der Freiheit. Hegel-Studien, V. 47, p. 145-151, 2014.

LUKÁCS, Georg. Geschichte und Klassenbewußtsein. Berlin: Malik, 1923 [História e consciência de classe. São Paulo: Martins Fontes, 2003].

MARCUSE, Herbert. Vernunft und Revolution. Neuwied: Luchterhand, 1962 [Razão e revolução. São Paulo: Paz e Terra, 1970].

MARCUSE, Herbert. One-dimensional man. Boston: Beacon Press, 1964 [O homem unidimensional: sobre a ideologia da sociedade industrial avançada. Campo Grande: Letra Livre, 2012].

MARCUSE, Herbert. Das Individuum in der ,Great Society“. In: Herbert Marcuse. Ideen zu einer kritischen Theorie der Gesellschaft. Frankfurt am Main: Suhrkamp, 1970. p. 157-184 [Ideias sobre uma teoria crítica da sociedade. Rio de Janeiro: Zahar, $1981]$.

MARX, Karl. Grundrisse der Kritik der politischen Ökonomie. Berlin: Dietz, 1953 [Grundrisse: Manuscritos econômicos de 1857-1858 - esboços da crítica da economia política. São Paulo: Boitempo, 2011].

MARX, Karl. Theorien über den Mehrwert. Frankfurt am Main: EVA, 1968.

MARX, Karl. Das Kapital. Berlin: Dietz. 1969 (1867). v. 1 [O capital, v. 1].

MARX, Karl. Lohnarbeit und Kapital. In: Karl Marx; Friedrich Engels. Werke Bd. 6. Berlin: Dietz 1973. p. 397-423 [Trabalho assalariado e capital].

MARX, Karl. Zur Judenfrage. (1844) In: Karl Marx; Friedrich Engels. Werke Bd. 1 (MEW 1). Berlin: Dietz, 1976 (1844). p. 347-377 [Sobre a questão judaica. São Paulo: Boitempo, 2010].

MARX, Karl; ENGELS, Friedrich. Manifesto do Partido Comunista, 1995 [diversas edições e traduções].

MARX, Karl; ENGELS, Friedrich. Die heilige Familie oder Kritik der kritischen Kritik: gegen Bruno Bauer \& Konsorten. In: Werke Bd. 2 (MEW 2), 1990, p. 3-224 [A sagrada família: a crítica da crítica. São Paulo: Boitempo, 2003].

MÖLLERS, Christoph. Staat als Argument. München: Beck, 2001.

MÖLLERS, Christoph. Der parlamentarische Bundesstaat: das vergessene Spannungsverhältnis von Parlament, Demokratie, und Bundesstaat. In: Josef Aulehner; Andreas Dengler; Karlheinz Konrad (orgs.). Föderalismus: Auflösung oder Zukunft der Staatlichkeit? München: Boorberg, 1997.

NEVES, Marcelo. Verfassung und positives Recht in der peripheren Moderne. Berlin: Dunckel \& Humblot, 1992 [A constitucionalização simbólica. São Paulo: Martins Fontes, 2007].

NIESEN, Peter. Über verfassungsgebende Gewalt [conferência]. Hamburg: Universität Hamburg 7. Mai 2014.

OFFE, Claus. Strukturprobleme des kapitalistischen Staats. Frankfurt am Main: Suhrkamp, 1972 [Problemas estruturais do estado capitalista. Rio de Janeiro: Tempo Brasileiro, 1984]. 
PIKETTY, Thomas. Capital in the twenty-first century. Cambridge: Harvard University Press, 2014 [O capital no século 21. Intrínseca, 2014].

QUINE, Williard van Orman. Logic and the reification of universals. In: Williard van Orman Quine. From a logical point of view. New York: Harper, 1961 [orig. 1951]. p. 102-129.

RAWLS, John. Eine der Theorie der Gerechtigkeit. Frankfurt am Main: Suhrkamp, 1979 [1971] [Uma Teoria da Justiça. São Paulo: Martins Fontes, 2002].

RAWLS, John. Politischer Liberalismus. Frankfurt am Main: Suhrkamp, 1998 [O liberalismo politico. São Paulo: Ática, 2000].

RAWLS, John. Gerechtigkeit als Fairneß: ein Neuentwurf. Frankfurt am Main: Suhrkamp, 2003 [Justiça como equidade: uma reformulação. São Paulo: Martins Fontes, 2003].

RAWLS, John. Die Idee des Politischen Liberalismus: Aufsätze 1978-1989. Frankfurt am Main: Suhrkamp, 2014.

RORTY, Richard. Philosophy and the mirror of nature. Princeton: Princeton University Press, 1980.

RORTY, Richard. Putnam and the relativist menace. The Journal of Philosophy, v. 9, p. 443-461, 1993.

RUDA, Frank. Hegels Pöbel. Konstanz: Konstanz Univ. Press, 2011.

SCHÄFER, Armin. Liberalization, inequality and democracy's discontent. In: Armin Schäfer; Wolfgang Streeck (orgs.). Politics in the age of austerity. Cambridge: Polity, 2013. p. 169-195.

SCHNÄDELBACH, Herbert. Vernunft. In: Ekkard Martens (org.). Philosophie: ein Grundkurs. Reinbek: Rowohlt, 1985. p. 37-76.

STREECK, Wolfgang. The crisis of democratic capitalism. New Left Review, v. 71, p. 1-14, 2011 <www.newleftreview.org/?view_2914> (13 May 2012) [As crises do capitalismo democrático. Novos estudos Cebrap, v. 92, p. 35-56, $2012<10.1590$ / S0101-33002012000100004>].

STREECK, Wolfgang. Volksheim oder Shopping Mall? Die Reproduktion der Gesellschaft im Dreieck von Markt, Sozialstruktur und Politik. (MPIfG Working Papers 11/5). Köln: Max-Planck-Institut für Gesellschaftsforschung, 2011 <www.mpifg.de/pu/ workpap/wp11-5.pdf> (Jan. 2014).

THEUNISSEN, Michael. Sein und Schein: die kritische Funktion der Hegelschen Logik. Frankfurt: Suhrkamp, 1980.

THORNHILL, Chris. A sociology of constitutions: constitutions and state legitimacy in historical-sociological perspective. Cambridge: Cambridge Univ. Press, $2011<10.1017 /$ CBO9780511895067>.

TILLY, Charles. European Revolutions 1492-1992. Oxford: Blackwell, 1995.

TUGENDHAT. Ernst. Einführung in die sprachanalytische Philosophie. Frankfurt am Main: Suhrkamp, 1976. 
WESCHE, Tilo. Demokratie und ihr Eigentum: von liberaler Marktfreiheit zur Wirtschaftsdemokratie. Zeitschrift für Philosophie, n. 3, p. 443-486, 2014.

WRIGHT, Gavin. Sharing the prize: the economics of the civil rights revolution in the American South. Cambridge: Harvard University Press, 2014.

Recebido em: 23 maio 2015

Aprovado em: $1^{\circ}$ dez. 2015

Autor correspondente:

Hauke Brunkhorst

Auf dem Campus 1

24943 Flensburg, Alemanha 